\title{
BASIC SOLUTIONS TO DEVELOP HUMAN RESOURCES FOR RESPONDING COVID-19 IN HO CHI MINH CITY HEALTH DEPARTMENT, VIETNAM
}

\author{
Pham Ngoc Nam \\ $\mathrm{PhD}$ candidate, University of Economics and Laws, \\ Vietnam National University Ho Chi Minh City, \\ Vietnam
}

\begin{abstract}
:
The COVID-19 pandemic has been raging and spreading worldwide, causing unprecedented negative impacts on the world economy and Vietnam. Facing the complicated development of the epidemic, it is required that we have solutions to limit the risks of negative impacts of the epidemic on the economy, ensure social security, thereby creating a foundation for maintaining stable and sustainable economic growth in the coming years. The development of human resource in health sectors in general and health stations of wards, communes and towns in Ho Chi Minh City is considered one of the urgent solutions to meet the long-term requirements effectively responding to the COVID-19 epidemic.
\end{abstract}

Keywords: human resources, Ho Chi Minh city, health stations, COVID-19

\section{Introduction}

After almost 2 years since its appearance, COVID-19 pandemic has spread to 223 countries and regions all over the world with over 256 million cases and 5.1 million death cases. Americas has been the most seriously impacted region during the pandemic so far, followed by Asia and Europe, while America, India and Brazil have the highest number of cases and deathsii.

Since the end of March 2021, the Delta variant has severely broken out in many countries, mostly in India and countries in Southeast Asia. After that, it has spread to over 130 countries across the world. In the previous total quantity of cases and deaths,

\footnotetext{
i Correspondence: email phamnamsyt@gmail.com

ii Figures accessed on November 20, 2021 from https://www.worldometers.info/coronavirus/. The number of infected cases and deaths in some regions are respectively registered as: Europe recorded 69.7 million 1.3 million; the U.S recorded 96.6 million and 2.4 million; Asia recorded 81.1 million and 1.2 million; Africa recorded 8.7 million and 221.852; Oceania recorded 344.257 and 4.061. In nations, the number of cases and deaths is respectively registered as: America recorded 48.39 million and 789.164; India recorded 34.5 million and 465.082; Brazil recorded 21.9 million and 612.177.
} 
those caused by this variant made up $80 \%$; at the climax stage, on average, it was reported to have the number of new cases from 700 thousand to 1 million per day. About Southeast Asia, it has recorded over 12.7 million cases and 271 thousand death cases, which made up 16,4\% cases and 23,7\% death cases in Asia and Indonesia is the most severe impacted nation by the Delta variant, followed by Philippines, Malaysia, Thailand and Viet Namiii.

This outbreak has had a considerable impact on preventing and controlling the pandemic in many countries, including developed countries that have modern medicine. Although many countries have a high rate of vaccination, it is more difficult to control and manage the campaigns for the ongoing spread of the pandemic. It made countries' medical systems to face with a new challenge; the pandemic was no longer a simple medical problem, it has had a profound effect on all aspects such as economics - society, social security and people's material \& spiritual lives. The damage caused by the pandemic is enormous despite being at different levels. Because the COVID-19 is unprecedented and unpredictable, many countries can't immediately have plans to control it but have to make an effort to keep updating the current situation of the pandemic. The COVID-19 has caused catastrophic damage to people, society \& economics and proved the restatement ability of the medical systems to make it able to the whole population and medical security is the world's first priority. WHO has just called for recovering the community medical systems, ensuring the whole population's health care and medical security in the COVID-19 period and further future. Medical systems following the initial health care direction should reach high efficiency; be capable of maintaining essential medical services for everyone, even if there is an emergency; invest in essential public medical functions with risk management to achieve sustainable ability ${ }^{\text {iv }}$.

\section{Results}

\subsection{The reality of Covid in Ho Chi Minh City}

Since the beginning of 2020, Viet Nam has undergone the fourth pandemic and has had 873,901 cases, ranked 40/223 countries and regions. With the rate of cases among a million people (which means for every 1 million people, there were 8,875 infections), Viet Nam ranked 154/223 countries and regions. During the 4th pandemic (since April 27, 2021), there has been 1,075,094 domestic cases recently recorded, included 883,564 people who were announced to recover (figured accessed as November 20, 2021).

In Ho Chi Minh city, on May 18 2021, the Delta variant was uncovered from 2 patients (patient 4514, patient 4583) in District 7 by Oxford University Clinical Research Unit - Hospital of Tropical Diseases in HCMC. As a result, it explained that samples

\footnotetext{
iii Indonesia had 4.3 million cases and 144 thousand deaths; Philippine had 2.8 million cases and 46 thousand deaths; Malaysia had 2.5 million cases and 30 thousand deaths; Thailand had 2.1 million and 20 thousand deaths.

iv "Building health systems resilience for universal health coverage and health security during the COVID19 pandemic and beyond" - World Health Organization 2021.
} 
which are from Revival Ekklesia Mission Vietnam (REM Vietnam) and others in HCMC were the same as the Delta variant. Later on, no other new variants from the patients have been detected through gene sequencing in the city. From January 12021 to November 20 2021,453,305 cases in the whole city have been publicized by Ministry of Health, included 17.360 cases died in the hospitals.

Being obliged to follow the government's motto as "every commune, every ward is 'an anti-epidemic fortress', everyone has to be a soldier, the center of service, a subject in preventing and controlling the epidemic". Under the direction of special Permanent Department of Ministry of Health supporting the city's preventing the COVID-19, Health of the city has planned the second spearhead-attack, which means we have to highly concentrate on the treatment work at facilities. In details, we have to start a pilot care relying on community for those who are F0 (the first spearhead-attack is aim to raise the ability of admitting and treating at the hospital).

The reality of anti-pandemic work has proved that communal medical stations play vital role in the prevention work. However, the proportion of the medical staff over Ho Chi Minh City' population is considered lowed compared with the whole country's and Hanoi's (7.42 and 6.06 respectively). Therefore, the support from other provinces across the country, especially the military medical force called by Ministry of National Defence, has successfully developed the mobile medical stations. The mobile medical stations along with the quick-response teams' activities have helped the Medical Stations be able to care and manage F0's health at home.

The Home Health Care for F0 model has obviously exerted its effects and has decreased the rate of people who have the capability of severe diseases and deaths. Besides, it has decreased the patient's post trauma and help them have a quick recovery. From August 232021 to September 30 2021, the number of F0 people who need to hospitalize was gradually reduced while there was a considerable increase in those who applied the Home Health Care. There have been 152,081 cases filly recovered and finished the quarantine at home.

At present, the military medical force called by Ministry of National Defence with 1,434 people working at mobile Medical Stations, managing, caring for COVID-19's patients in quarantine at home from 28/08/2021 to 01/11/2021 had 1,176 people who completed their missions; it is predicted that 258 people would have completed their tasks as supporters (86 mobile Medical Stations) by the end of November, 2021. Thus, the target number of people working for medical stations must be added with the population in wards' scale and local's particular to recruit, supply or alternate the workforce called by Ministry of National Defence is necessary in current period.

In the current situation, supporters from other departments to respond the pandemic have completed their mission while Ho Chi Minh Health Department is still facing with COVID-19. Preparing human resources for medical stations is very urgent. Therefore, it is required to enact particular policy to carry out. The medical workforce be supplied by the medical human resources who are available in the local (private 
healthcare, retired medics), but medical staff also have no anxiety while working at Medical Stations.

\section{Basic solutions to develop human resources for grassroots in Ho Chi Minh City about preventing Covid - 19}

Ho Chi Minh City is over-populated. According to statistics, the city has 310 Medical Stations, including 174/310 Medical Stations with over 20.000 people. In 174 Medical Stations which have over 20,000 people, there are 40 Medical Stations have 50,000 people, 3 Medical Stations' population is over 100,000 people. Vinh Loc A's Medical Station has the most population with the number of 125,000, 6.25 times as much as the norm of 20,000 population but it only has $10 \mathrm{staff} / \mathrm{station}$. Thus, the ceiling has to be adjusted according to Joint Circular 08/2007/TTLT-BYT- BNV to suit the over-populated situation of the city:

Firstly, to ensure Medical Stations' human resources in caring people's health and preventing and controlling the pandemic in current period, The Health Department suggested that Medical Stations' payroll ceiling should be adjusted to increase according to Joint Circular 08/2007/TTLT-BYT- BNV 5 , the maximum of a station is 20 staff and the minimum is 10 staff instead of $10 \mathrm{staff} /$ station or lower (people who are present to work at Medical Stations include officials and workers). As a result, the total of staff allocated in 2022 to 310 Medical Stations in wards of the city is 3.991 staff according to suggested standard, higher than those in 2021 which had 1,704 staff.

Secondly, the increasing Medical Stations' human resources policy: it is difficult to recruit medical staff for Medical Stations in wards at present. To utilize the norm payroll as suggested effectively, it is necessary to enact attractive policy and increase Medical Stations' workforce, suggest a pilot program which offers 18-month internship and provides practising certificates to new graduate doctors. According to it, instead of applying and fully bearing the cost to have an internship at hospitals for 18 months, new graduate doctors was suggested to practice at Medical Stations for 12 months and General Hospital for 6 months (hospitals are not allowed to receive internship fee, budget will pay training costs). During the internship, doctors will be offered to have part of living cost paid, the monthly support living standard is 1.5 times as much as region's salary. Applying the same policy, new graduate nursing, midwives, technicians will have a 9month internship at Medical Stations.

Thirdly, policy to attract Medical Stations' human resources: in previous pandemic period, the City called for 5,202 volunteers who are retired medics, private medical human resources, religious volunteers, volunteers recovered after being F0 to help in caring patients suffered from COVID-19 at Field hospital, Hospital treating COVID-19 and participate in isolation facilities, sampling, tracing, vaccinating support, checkpoints, lockdown areas, the mobile medical station and other backup work, in Thu Duc city and Districts, Wards. Therefore, the medical staff were supported in preventing the pandemic. About using the model mentioned above to supply the workforce for Medical Stations, apart from recruitment with labour contract and official recruitment, 
service contract and professional cooperation contract with retired doctors, retired medical staff, volunteers working at Medical Stations have to be supplied along with monthly income supports based on minimum salary standard. In the current context, each health station needs to mobilise 2 retired doctors, 4 other retired medical staff and 2 volunteers with estimated budget to support their incomes of over 16 billion VND. According to Ho Chi Minh City Department of Health, each Medical Stations required 2 retired doctors, 4 retired medical staff and 2 volunteers without medical professional with the total estimated cost in monthly income supports is about over 16 billion VNĐ. For people who are at working age, according to the Government's Resolution 102/NQCP on July 32020 about solutions for educational and medical careers payroll: In term of labour contracts at specialized, professional positions which are in the norm of the number of people working their tasks at Health Center in Districts, Wards, Thu Duc city and Medical Stations in wards are allowed to have under-12-month labour contracts while they are waiting for official admission but to use their own budgets. Because of the pandemic situation, Health Center's income has considerable decreased and been in difficult time, Department of Health suggested the labour contract mentioned above must have payment support by the City's Budget instead of using their own budgets, the salary rate is determined on the basis of worker's qualification according to Resolution 204/2004/NĐ-CP. Following to Department of Health's estimation, the total number of people who had been working at Medical Stations until October 312021 is 2,014, including 1,729 officials and 285 labour contracts. Each Medical Stations is expected to have 2 labour contracts. The total number of labour contracts of 310 Medical Stations is 620 people with an estimated budget of over 3 billion VNĐ.

Fourthly, policy to make medical staff feel no anxiety while working at Medical Stations: on January 27 2015, Ho Chi Minh City People's Committee enacted Decision 06/2015/QĐ-UBND about attracting, supporting officers and officials working at health facilities which belong to Ho Chi Minh City's medial backup field. Because some support modes are no longer suitable and cannot assure medical staff at health facilities and medial backup field, it is necessary to enact a monthly support policy to increase income, lessen difficulty to them, especially doctors in order that they can work with peace in mind. This policy is aim to stabilize and maintain medical staff to comfortably work at health facilities.

To sum up, the shortage of human resources for grassroots health's in the City needs to combine other solutions beside income support policy. The Health Department of the City has implemented the compensation policy of promotion opportunities for officers working at medical facilities such as receive priority in training, planning, leadership position appointment, management, commending and rewarding. In addition, Department of Health in the city is intensely investing in infrastructure and equipment for Medical Stations, ensuring that medicines and supplies for Medical Stations to facilitate doctors at Medical Stations in wards have chances to practice and improve professional qualifications. Besides, it is important to have a tight combination 
between backup work and treatment, between area's medical facilities and upstream ones to meet the requirement of COVID-19 long-term prevention in these new situations.

\section{Conclusions}

On the basis of the global generalization of COVID-19 pandemic including HCM city, the article has considered and come up with some solutions to develop the medical facilities in general and medical station in wards in particular in HCM city in order to meet the requirement of COVID-19 long-term prevention in these new situations.

\section{Conflict of Interest Statement}

The author declares no conflicts of interests.

\section{About the Author}

Pham Ngoc Nam has been working at Department of Health of Ho Chi Minh City and is pursuing his $\mathrm{PhD}$ degree at University of Economics and Laws, Vietnam National University Ho Chi Minh City, Vietnam.

\section{References}

1. COVID Live Update: 271,030,375 Cases and 5,327,805 Deaths from the Coronavirus - Worldometer, 2021). https://www.worldometers.info/coronavirus/

2. Cổng Thông Tin Của Bộ Y Tế Về Đại Dịch Covid-19 https://covid19.gov.vn/

3. Nguyen Quang Thuan (2020). Impacts of Covid-19 and some solutions for prevention in Vietnam in the upcoming stage. accessed from https://www.tapchicongsan.org.vn/web/guest/kinh-te/-/2018/819611/tac-dongcua-dai-dich-covid-19\%C2\%A0va-mot-so-giai-phap-chinh-sach-cho-viet-namtrong-giai-doan-toi.aspx

4. Ho Chi Minh City Department of Health - preventing COVID-19 statistics.

5. Joint Circular 08/2007/TTLT-BYT- BNV on June 05, 2007 of Ministry of Public Health, Ministry of domestic affairs instructing career payroll norms in Government's health facilities.

6. World Health Organization 2021 - "Building health systems resilience for universal health coverage and health security during the COVID-19 pandemic and beyond". 

will be applied to their work. Under the terms of this license, no permission is required from the author(s) or publisher for members of the community to copy, distribute, transmit or adapt the article content, providing a proper, prominent and unambiguous attribution to the authors in a manner that makes clear that the materials are being reused under permission of a Creative Commons License. Views, opinions and conclusions expressed in this research article are views, opinions and conclusions of the author(s). Open Access Publishing Group and European Journal of Public Health Studies shall not be responsible or answerable for any loss, damage or liability caused in relation to/arising out of conflicts of interest, copyright violations and inappropriate or inaccurate use of any kind content related or integrated into the research work. All the published works are meeting the Open Access Publishing requirements and can be freely accessed, shared, modified, distributed and used in educational, commercial and non-commercial purposes under a Creative Commons Attribution 4.0 International License (CC BY 4.0). 